\title{
A CPW-Fed Dual-Band-Notched Antenna with Sharp Skirt Selectivity for UWB Applications
}

\author{
Dacheng Dong, Shaojian Chen, Zhouying Liao, and Gui Liu \\ College of Physics \& Electronic Information Engineering, Wenzhou University, Zhejiang 320535, China \\ Correspondence should be addressed to Gui Liu; iitgliu2@gmail.com
}

Received 2 March 2014; Revised 25 May 2014; Accepted 30 May 2014; Published 23 June 2014

Academic Editor: Renato Cicchetti

Copyright (C) 2014 Dacheng Dong et al. This is an open access article distributed under the Creative Commons Attribution License, which permits unrestricted use, distribution, and reproduction in any medium, provided the original work is properly cited.

\begin{abstract}
A coplanar waveguide- (CPW-) fed dual-band-notched antenna with sharp skirt selectivity for ultrawideband (UWB) applications is presented. The proposed antenna is composed of a radiant patch with a C-shaped slot and a C-shaped stub on the back surface of the substrate. By using the C-shaped slot and the C-shaped stub, dual-band-notched characteristics can be generated. In this way, a more practical and effective approach to design an UWB antenna with sharp notched-band-edge selectivity is developed. The measurement results show dual notched bands of 4.96-5.42 GHz and 5.71-5.91 GHz, which can reject the interference between IEEE 802.11a bands $(5.15-5.35 \mathrm{GHz}$ and $5.725-5.825 \mathrm{GHz})$ and UWB systems. The fabricated antenna shows good omnidirectional radiation patterns with acceptable gain and group delay.
\end{abstract}

\section{Introduction}

Ultrawideband (UWB) technology has recently become one of the most promising candidates for short-range highbandwidth indoor and outdoor wireless communications systems. Since the UWB systems occupy an extremely wide band from 3.1 to $10.6 \mathrm{GHz}$, it is necessary to reject the interference with the existing wireless local area network (WLAN) for IEEE $802.11 \mathrm{a}$ operating at $5.15-5.35 \mathrm{GHz}$ and 5.725-5.825 GHz. As a critical component of an UWB system, band-notched UWB antennas have been widely investigated [1-12]. Numerous techniques have been proposed to realize band-notched function such as utilizing parasitic elements [1], defected ground structure [2], T-shaped stub embedded in the slot [3], modified split-ring resonator (SRR), and many kinds of slots, such as circle-like slot [4], F-shaped slot [5], Tshaped slot [6], E-shaped slot [7], C-shaped slot [8], inverted V-shaped slot [9], inverted S-shaped slot [10], inverted Tshaped slot [11], and П-shaped slot [12].

However, most band-notched antennas cannot provide sharp notched-band-edge selectivity and dual-band-notched characteristics for IEEE 802.11a, which results in the fact that the entire 5-6 GHz frequency band has been completely rejected [13]. The signal contained in the frequency band of $5.35-5.725 \mathrm{GHz}$ is also rejected, which results in severe system performance degradation. Several approaches have been proposed to achieve sharp band-notched characteristics, for instance, inserting a half-wavelength C-shaped slot in the patch and adding two half-wavelength stepped impedance resonators around the feed line [14], slitting an open-ended quarter-wavelength split slot on the back of the feed and a short-ended half-wavelength split-ring slot near the stepped slot [15], using double open-circuited stubs [16], and employing a pair of Y-shaped strips to the annular ring and an inverted V-shaped slot on the patch [17]. However, few of the reported notch-band UWB antennas with sharp skirt selectivity could just cover $5.15-5.35 \mathrm{GHz}$ and $5.725-$ $5.875 \mathrm{GHz}[14]$.

To realize compact UWB system, planar dipole antennas can be a good candidate because of their attractive merits such as compact size, low cost, ease of fabrication, and easy integration with feed network. Several novel planar dipole antenna structures have been proposed to widen the impedance matching bandwidth [18-22]. Cappelletti et al. present a drop-shaped dipole antenna which can be used to realize compact array antennas or to reduce the spurious radiation level in the direction of feeding line [18]. A planar dipole UWB antenna with two semielliptical-ended arms connected by a shorting bridge is proposed to achieve enhanced impedance and gain performance [19]. Printed 


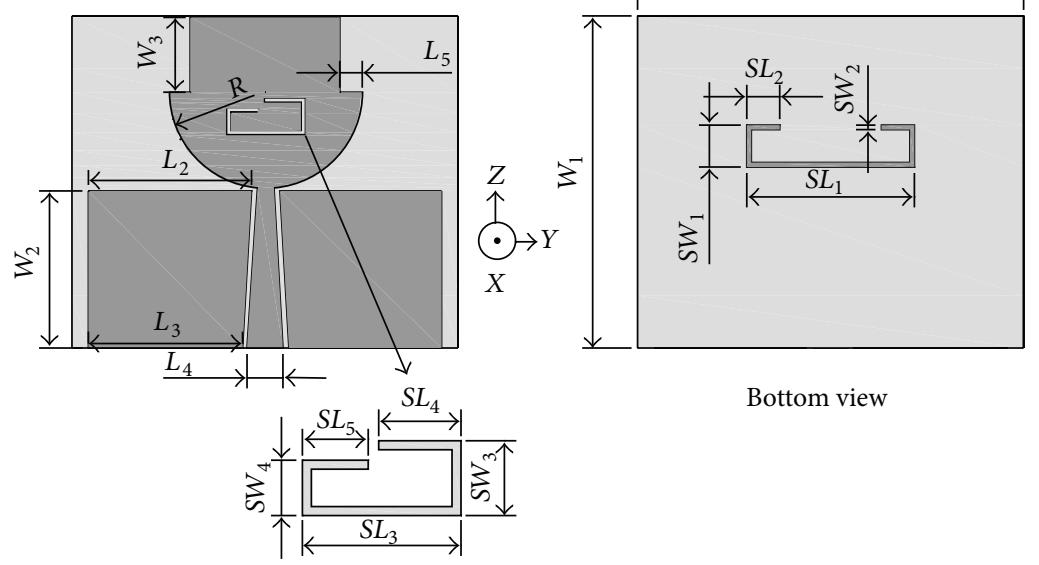

Top view

(a)

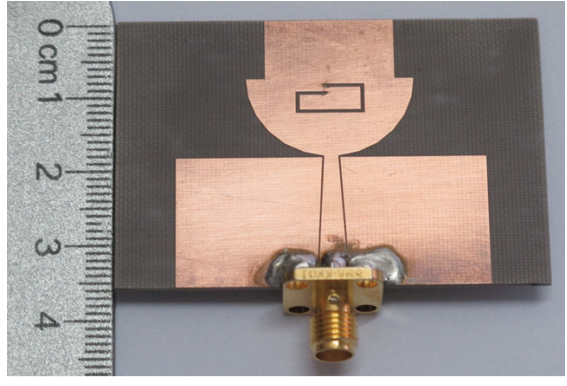

Top view

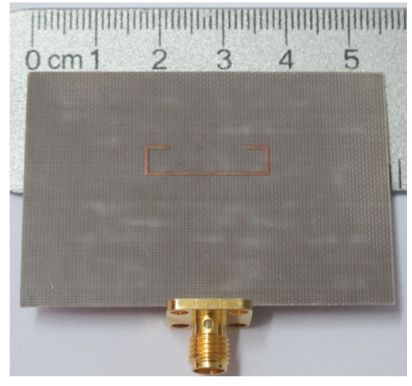

Bottom view

(b)

Figure 1: Geometry of the proposed antenna. (a) Structure and (b) photographs.

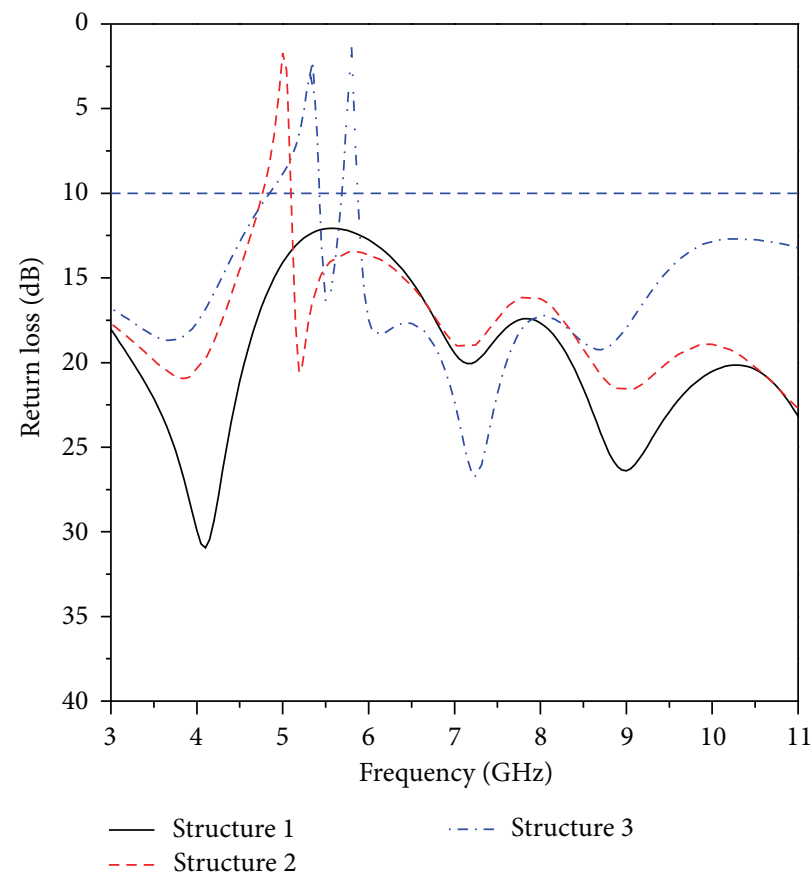

FIGURE 2: Simulated return loss of the proposed antenna with three configurations of slot and stub. 


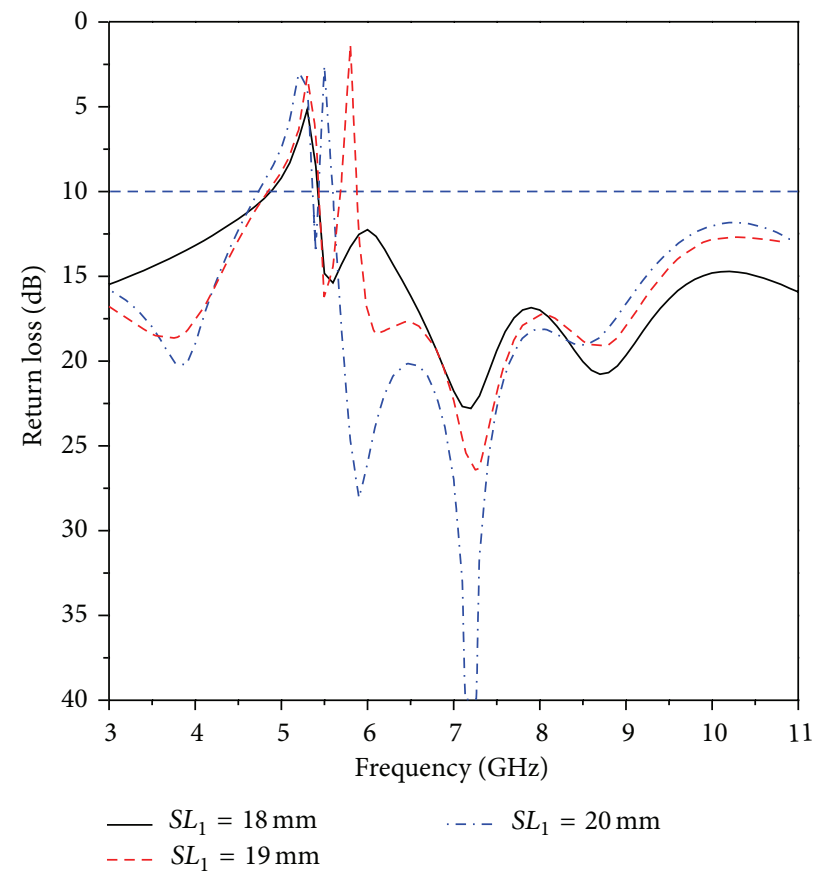

FIGURE 3: Simulated return loss of the proposed antenna with different values of $S L_{1}$.

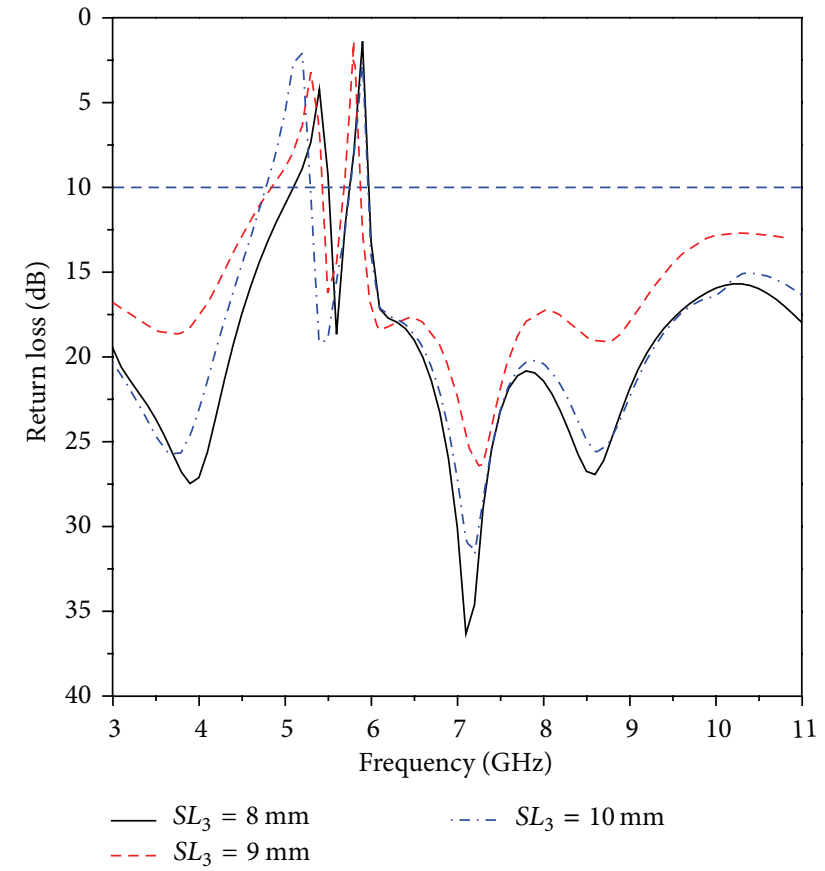

FIGURE 4: Simulated return loss of the proposed antenna with different values of $S L_{3}$.

dipole antenna with integrated balun provides wideband impedance matching with miniature size [20]. In [21], a novel wideband balanced loop-dipole composite antenna with end-fire radiation is presented. The measured impedance bandwidth is $129 \%$ (from 3.26 to $15 \mathrm{GHz}$ ). In [22], a differentially fed magnetoelectric dipole (ME dipole) is designed

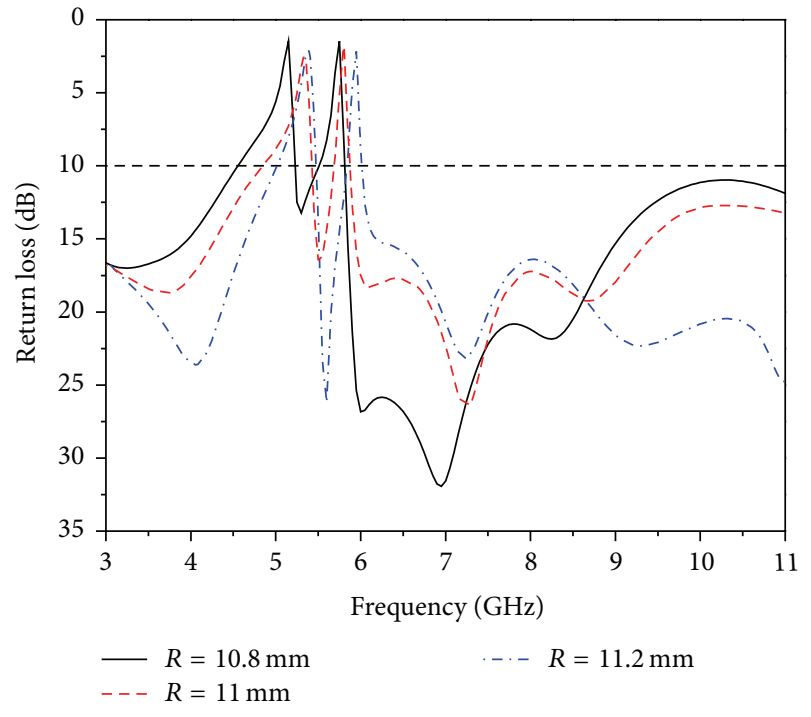

FIGURE 5: Simulated return loss of the proposed antenna with different values of $R$.

by introducing two slots in the dipole arms so providing an ultrawideband impedance matching. However, these antennas often suffer from high profiles or the structures are too complicated to be fabricated and assembled.

In this study, a novel band-notched UWB antenna with sharp selectivity is presented. The proposed antenna consists of a radiant patch with an embedded C-shaped slot and a Cshaped stub on the back surface of the substrate. The desired notched band can be easily achieved by properly designing a C-shaped slot and a C-shaped stub. In this way, two stop bands with sharp skirt selectivity can be obtained. 
This paper is organized as follows. The antenna structure and details of the parameter optimizations are introduced in Section 2. In addition, the surface current distributions are also provided and analyzed. Section 3 shows the measurement results of the proposed antenna, namely, its reflection coefficient, radiation patterns, and gain. Finally, Section 4 presents the conclusion for this research.

\section{Antenna Configuration}

The geometry of the proposed dual-band-notched UWB antenna is depicted in Figure 1. The antenna is fabricated on a $38 \mathrm{~mm} \times 44 \mathrm{~mm} \times 0.8 \mathrm{~mm}$ F4B substrate with relative permittivity 2.55 , loss tan 0.003 , and thickness of $0.8 \mathrm{~mm}$. The antenna consists of a radiator with a C-shaped slot, a taped CPW line on the front of the substrate, and a Cshaped stub on the back surface of the substrate. The key innovation in the proposed design is to use both the Cshaped slot and the C-shaped stub to achieve dual-notchedband characteristics with sharp skirt selectivity. The proposed antenna is fed by the coplanar waveguide (CPW) due to its significant advantages compared to microstrip-fed lines, for instance, unipolar configuration, easy integration, compact size, and ease of manufacture. Furthermore, the tapered CPW could improve the impedance matching in a wide frequency band.

\section{Results and Discussions}

3.1. Return Loss. Figure 2 shows the return loss of the proposed antenna under three structures: (1) Structure 1: without the slot and the stub, (2) Structure 2: with the slot but without the stub, and (3) Structure 3: with both the slot and the stub. As can be observed from Figure 2, the slot introduces a single-band-notched function, while the dual-band-notched function is achieved by employing both the slot and the stub.

To further investigate the effect of the stub on the return loss of the proposed antenna, various lengths of the stub have been studied and optimized. Figure 3 shows the return loss of the proposed antenna with different lengths of the parameter $S L_{1}$. From this figure, it appears that, by adjusting the length of the parameter $S L_{1}$, the resonance frequency of the rejected band can be properly tuned.

As illustrated in Figure 4, the length of the C-shaped slot has a great effect on the lower notched frequency band, while it does not affect the higher notched frequency band.

As shown in Figure 5, it is observed that, when the parameter $R$ increases from $10.8 \mathrm{~mm}$ to $11.2 \mathrm{~mm}$, the center frequencies of the dual-notched-band increase. Therefore, the center frequencies of the dual-notched-band are controllable by varying the parameter $R$.

Figure 6 shows the simulated and measured return loss characteristics of the proposed antenna. Slight discrepancy between the measurement and the simulation results could be due to the effects of the SMA connector, which has not been included in the numerical model. The $-10 \mathrm{~dB}$ bandwidth is from 3.1 to $10.6 \mathrm{GHz}$ with sharp

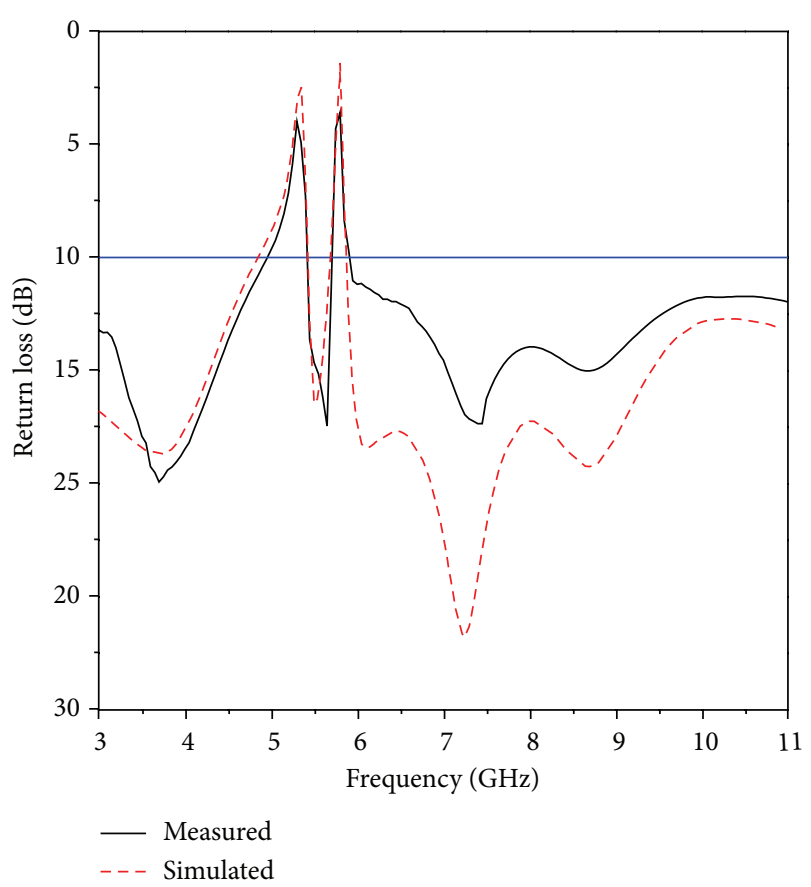

FIgURE 6: Simulated and measured return loss of the proposed antenna.

notched-band-edge selectivity $(4.96-5.42 \mathrm{GHz}$ and $5.71-$ $5.91 \mathrm{GHz}$ ).

The optimized parameters of the proposed antenna are the following: $L_{1}=44 \mathrm{~mm}, L_{2}=19 \mathrm{~mm}, L_{3}=18 \mathrm{~mm}, L_{4}=$ $4 \mathrm{~mm}, L_{5}=2.5 \mathrm{~mm}, W_{1}=38 \mathrm{~mm}, W_{2}=18 \mathrm{~mm}, W_{3}=8.5 \mathrm{~mm}$, $S L_{1}=19 \mathrm{~mm}, R=11 \mathrm{~mm}, S L_{2}=3.7 \mathrm{~mm}, S L_{3}=9 \mathrm{~mm}, S L_{4}=$ $4.7 \mathrm{~mm}, S L_{5}=3.7 \mathrm{~mm}, S W_{1}=4.8 \mathrm{~mm}, S W_{2}=0.5 \mathrm{~mm}, S W_{3}=$ $4.2 \mathrm{~mm}$, and $S W_{4}=2.6 \mathrm{~mm}$.

3.2. Current Distribution. Figure 7 illustrates the surface current density computed at the center frequencies of the two notched-bands. As can be observed in Figure 7(a), for the lower-frequency notch $(4.96-5.42 \mathrm{GHz})$, the current density is concentrated close to the C-shaped slot, while Figure 7(b) shows that the current is primarily concentrated around the C-shaped stub for the upper-frequency band $(5.71-5.91 \mathrm{GHz})$.

In order to investigate the radiation mechanisms of the notched-band elements, simulated vector current distributions at both notched frequencies $(5.2 \mathrm{GHz}$ and $5.8 \mathrm{GHz})$ are illustrated in Figure 8. As shown in Figure 8(a) for $5.2 \mathrm{GHz}$, the currents flow in the opposite direction along the inner and outer sides of the C-shaped slot. Therefore, the resultant fields cancel each other and consequently the antenna does not radiate electromagnetic energy in the space. Thus, the C-shaped slot can be used to filter out the narrower band emissions. As it can be seen from Figure 8(b), due to the symmetry of the C-shaped stub, the directions of the surface currents along the $y$-direction on the C-shaped stub are opposite to each other. Therefore, the resultant fields are canceled out and high field attenuation is obtained at the notched frequency. Thus, the proposed antenna does not 


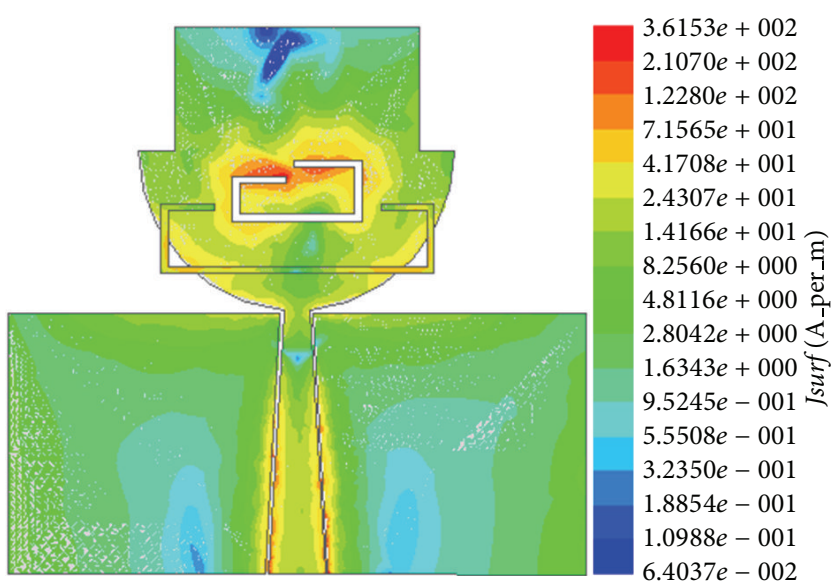

(a)

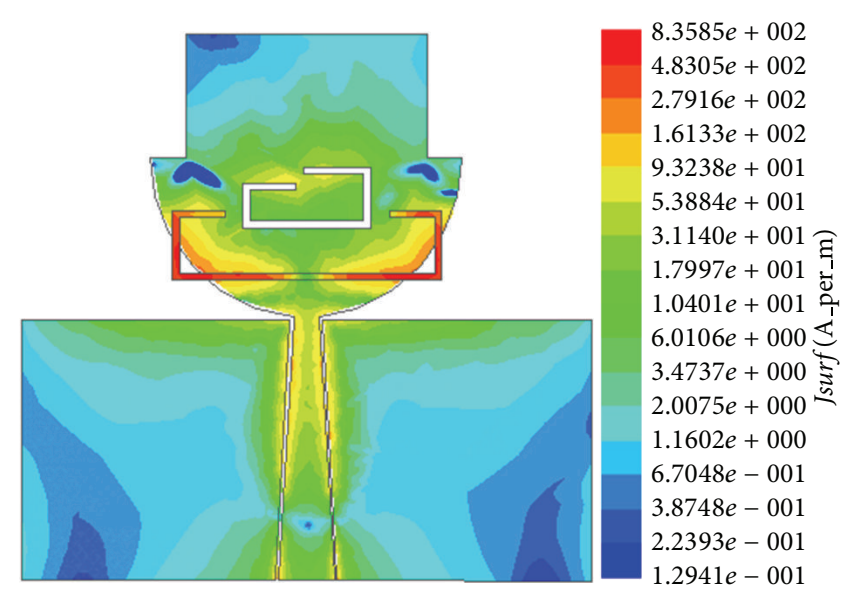

(b)

FIGURE 7: Simulated surface current distributions of the proposed antenna at different frequencies. (a) $5.2 \mathrm{GHz}$ and (b) $5.8 \mathrm{GHz}$.

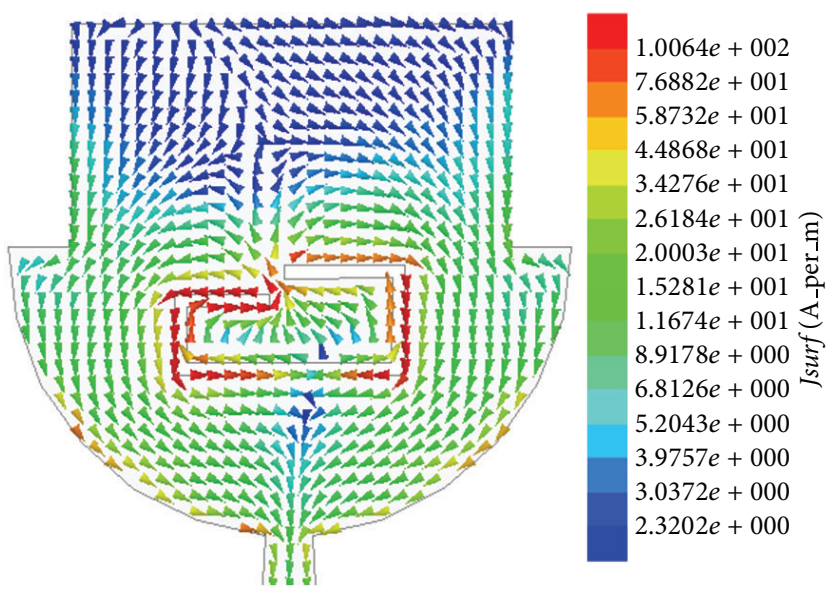

(a)

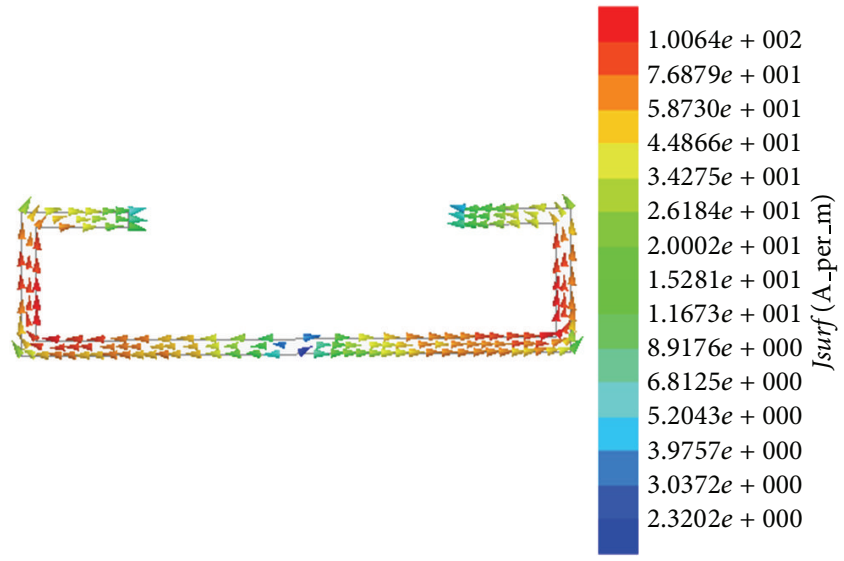

(b)

FIGURE 8: Simulated vector current distributions at different notch frequencies. (a) $5.2 \mathrm{GHz}$ and (b) $5.8 \mathrm{GHz}$.

radiate efficiently around the filter structure at the higher notched frequency.

3.3. Radiation Patterns and Gain. Figure 9 shows the measured normalized far field radiation patterns in E-plane $(x z$ plane, spherical angle phi $\left.=0^{\circ}\right)$ and $\mathrm{H}$-plane $(x y$-plane, spherical angle theta $=90^{\circ}$ ) at $5.5 \mathrm{GHz}, 7 \mathrm{GHz}$, and $10 \mathrm{GHz}$, respectively. As can be seen from Figure 9(a), two nulls are observed in the antenna broadside direction at the frequencies of $7 \mathrm{GHz}$ and $10 \mathrm{GHz}$. The main reason for these two nulls is that, as the frequency increases, the levels of the higher order modes and of the cross-polarization increase too. However, it can be observed that the $\mathrm{H}$-plane patterns are almost omnidirectional for the three considered frequencies.

The measured antenna peak gain, reported in Figure 10, shows two significant gain decrements at about $5.3 \mathrm{GHz}$ and $5.8 \mathrm{GHz}$, which confirm the filtering effects. For the other frequencies outside the notched bands, a relatively flat gain is observed over the entire UWB band.
3.4. Group Delay Characteristics. As shown in the previous sections, the proposed antenna exhibits ultrawideband characteristics in the frequency domain. For UWB systems, the time-domain response is also a critical feature [18]. Group delay is a very important parameter of time-domain analysis. It is desirable to keep a constant group delay over the entire frequency band to avoid undesirable distortion of the radiated and received pulses. To evaluate the group delay of the UWB systems, a pair of identical proposed antennas is placed face to face at a distance of $30 \mathrm{~cm}$. As shown in Figure 11, the variation of the group delay, computed by means of the scattering parameter $S_{21}$, is less than 560 ps with the average of $1.1 \mathrm{~ns}$ across the whole UWB frequency band except at both notched bands. In both notched bands, the presence of the band-notch filters deteriorates the radiation performance and the impedance matching, which results in inaccurate and negative group delay. Since the proposed antenna shows an acceptable group delay in the transmission of UWB signals, it is suitable for the UWB communication applications. 


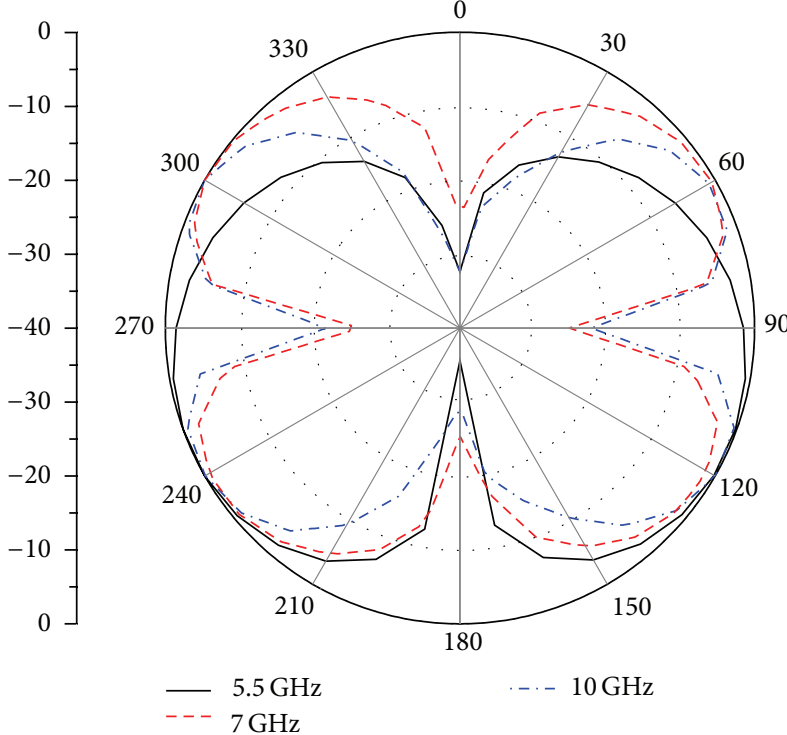

(a)

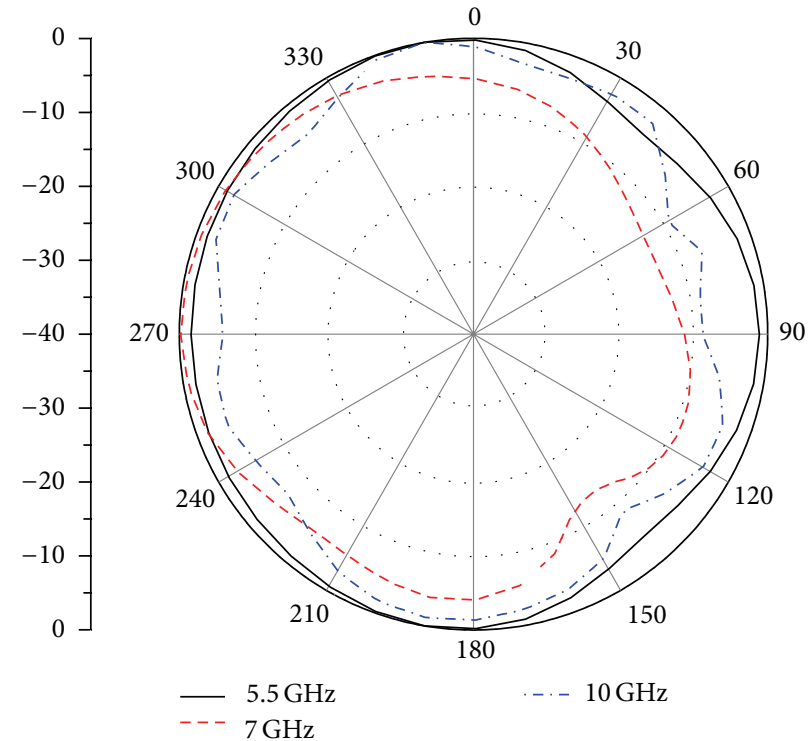

(b)

FIGURE 9: Normalized radiation patterns of the proposed antenna for the three different frequencies taken into consideration: (a) E-plane and (b) H-plane.

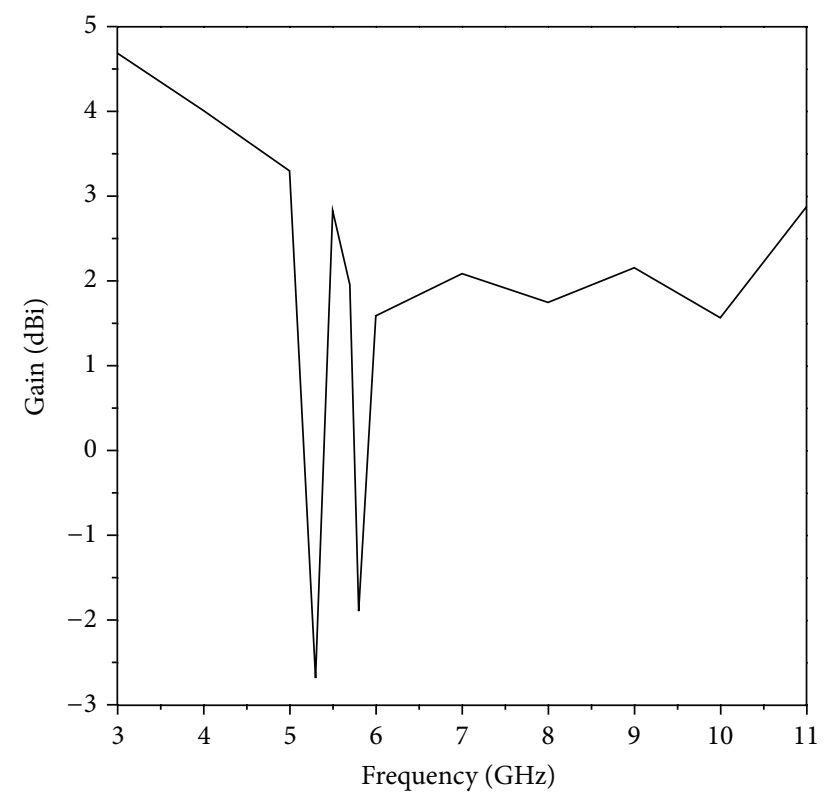

FIGURE 10: Measured peak gain of the proposed antenna.

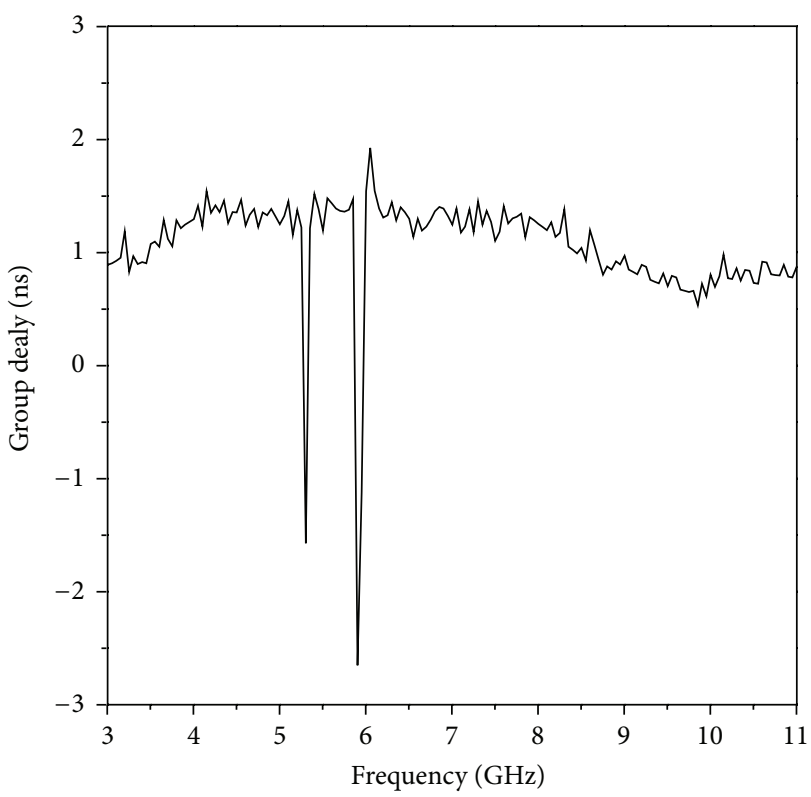

FIGURE 11: Group delay of the proposed antenna systems.

\section{Conclusion}

In this paper, a dual-notched-band antenna with sharp notched-band-edge selectivity has been proposed. By using the slot in the radiator and the stub on the back surface of the substrate, dual-notched-band functions are realized. Specifically, measured results show that the intermediate frequency range between 5.43 and $5.7 \mathrm{GHz}$ can be utilized with our proposed antenna, while it is rejected by other WLAN bandnotched UWB antennas. Furthermore, the proposed antenna has demonstrated good omnidirectional radiation pattern, acceptable gain, and group delay. Consequently, the proposed antenna could be a good candidate for the UWB applications.

\section{Conflict of Interests}

The authors declare that there is no conflict of interests regarding the publication of this paper. 


\section{Acknowledgments}

This work was supported in part by the National Natural Science Foundation of China under Grant no. 61340049, Zhejiang Provincial Natural Science Foundation of China under Grant no. LY12F04002, Zhejiang Qianjiang Talents Project under Grant no. QJD1202003, and Technology Foundation for Selected Overseas Chinese Scholar under Grant no. R20130601.

\section{References}

[1] J.-M. Lee, K.-B. Kim, H.-K. Ryu, and J.-M. Woo, "A compact ultrawideband MIMO antenna with WLAN band-rejected operation for mobile devices," IEEE Antennas and Wireless Propagation Letters, vol. 11, pp. 990-993, 2012.

[2] A. Nouri and G. R. Dadashzadeh, "A compact UWB bandnotched printed monopole antenna with defected ground structure," IEEE Antennas and Wireless Propagation Letters, vol. 10, pp. 1178-1181, 2011.

[3] W. Jiang and W. Q. Che, "A novel UWB antenna with dual notched bands for WiMAX and WLAN applications," IEEE Antennas and Wireless Propagation Letters, vol. 11, pp. 293-296, 2012.

[4] S. R. Emadian, C. Ghobadi, J. Nourinia, M. H. Mirmozafari, and J. Pourahmadazar, "Bandwidth enhancement of CPW-Fed circle-like slot antenna with dual band-notched characteristic," IEEE Antennas and Wireless Propagation Letters, vol. 11, pp. 543546, 2012.

[5] R. Karimian, H. Oraizi, S. Fakhte, and M. Farahani, "Novel F-shaped quad-band printed slot antenna for WLAN and WiMAX MIMO systems," IEEE Antennas and Wireless Propagation Letters, vol. 12, pp. 405-408, 2013.

[6] C.-Y.-D. Sim, W.-T. Chung, and C.-H. Lee, "Compact slot antenna for UWB applications," IEEE Antennas and Wireless Propagation Letters, vol. 9, pp. 63-66, 2010.

[7] N. Ojaroudi, M. Ojaroudi, and N. Ghadimi, "Dual bandnotched small monopole antenna with novel W-shaped conductor backed-plane and novel T-shaped slot for UWB applications," IET Microwaves, Antennas and Propagation, vol. 7, no. 1, pp. 8-14, 2013.

[8] P. Gao, L. Xiong, J. B. Dai, S. He, and Y. Zheng, "Compact printed wide-slot UWB antenna with 3.5/5.5-GHz dual bandnotched characteristics," IEEE Antennas and Wireless Propagation Letters, vol. 12, pp. 983-986, 2013.

[9] S. Mohammadi, J. Nourinia, C. Ghobadi, and M. Majidzadeh, "Compact CPW-fed rotated square-shaped patch slot antenna with band-notched function for UWB applications," Electronics Letters, vol. 47, no. 24, pp. 1307-1308, 2011.

[10] B. Li, J. Hong, and B. Wang, "Switched band-notched UWB/dual-band WLAN slot antenna with inverted S-shaped slots," IEEE Antennas and Wireless Propagation Letters, vol. 11, pp. $572-575,2012$.

[11] N. Ojaroudi and N. Ghadimi, "UWB small slot antenna with WLAN frequency band-stop function," Electronics Letters, vol. 49, no. 21, pp. 1317-1318, 2013.

[12] A. Valizade, C. Ghobadi, J. Nourinia, and M. Ojaroudi, "A novel design of reconfigurable slot antenna with switchable band notch and multiresonance functions for uwb applications," IEEE Antennas and Wireless Propagation Letters, vol. 11, pp. 1166-1169, 2012.
[13] Q. X. Chu and T. G. Huang, "Compact UWB antenna with sharp band-notched characteristics for lower WLAN band," Electronics Letters, vol. 47, no. 15, pp. 838-839, 2011.

[14] T. Li, H. Zhai, L. Li, C. Liang, and Y. Han, "Compact UWB antenna with tunable band-notched characteristic based on microstrip open-loop resonator," IEEE Antennas and Wireless Propagation Letters, vol. 11, pp. 1600-1603, 2012.

[15] Q. Chu, C. Mao, and H. Zhu, "A compact notched band UWB slot antenna with sharp selectivity and controllable bandwidth," IEEE Transactions on Antennas and Propagation, vol. 61, no. 8, pp. 3961-3966, 2013.

[16] A. A. Gheethan and D. E. Anagnostou, "Dual band-reject UWB antenna with sharp rejection of narrow and closely-spaced bands," IEEE Transactions on Antennas and Propagation, vol. 60, no. 4, pp. 2071-2076, 2012.

[17] Z. L. Zhou, L. Li, and J. S. Hong, "Compact UWB printed monopole antenna with dual narrow band notches for WiMAX/WLAN bands," Electronics Letters, vol. 47, no. 20, pp. 1111-1112, 2011.

[18] G. Cappelletti, D. Caratelli, R. Cicchetti, and M. Simeoni, "A low-profile printed drop-shaped dipole antenna for wideband wireless applications," IEEE Transactions on Antennas and Propagation, vol. 59, no. 10, pp. 3526-3535, 2011.

[19] X. N. Low, Z. N. Chen, and T. S. P. See, "A UWB dipole antenna with enhanced impedance and gain performance," IEEE Transactions on Antennas and Propagation, vol. 57, no. 10, pp. 2959-2966, 2009.

[20] W. S. Yeoh, K. L. Wong, and W. S. T. Rowe, "Wideband miniaturized half bowtie printed dipole antenna with integrated balun for wireless applications," IEEE Transactions on Antennas and Propagation, vol. 59, no. 1, pp. 339-342, 2011.

[21] W. J. Lu, W. H. Zhang, K. F. Tong, and H. B. Zhu, "Planar wideband loop-dipole composite antenna," IEEE Transactions on Antennas and Propagation, vol. 62, no. 4, pp. 2275-2279, 2014.

[22] M. J. Li and K. M. Luk, "A differential-fed magneto-electric dipole antenna for UWB applications," IEEE Transactions on Antennas and Propagation, vol. 61, no. 1, pp. 92-99, 2013. 

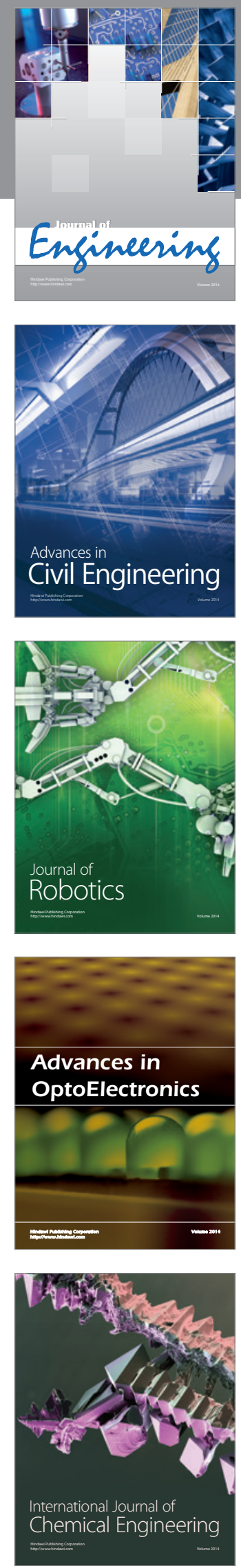

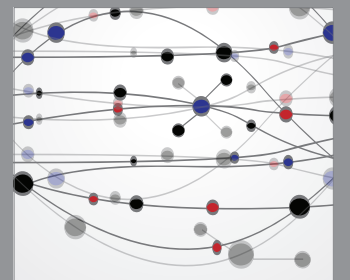

The Scientific World Journal
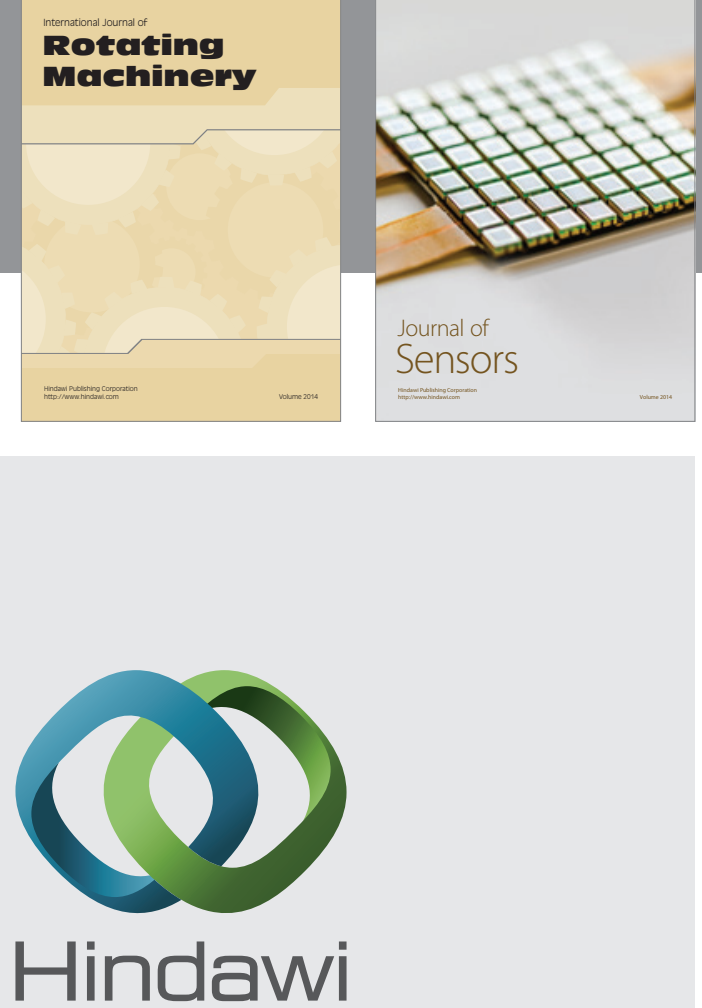

Submit your manuscripts at http://www.hindawi.com
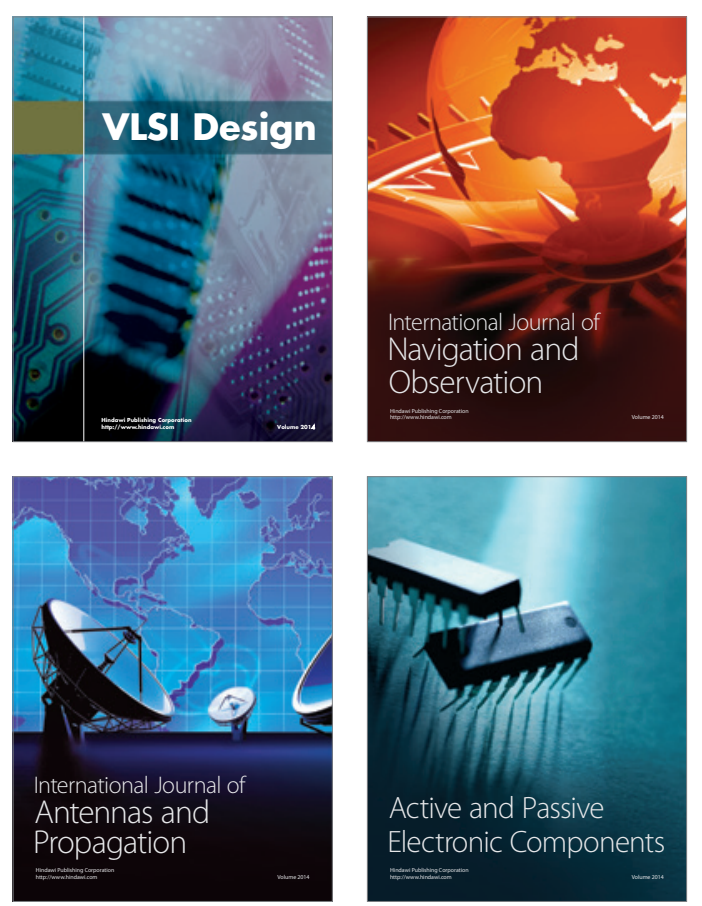
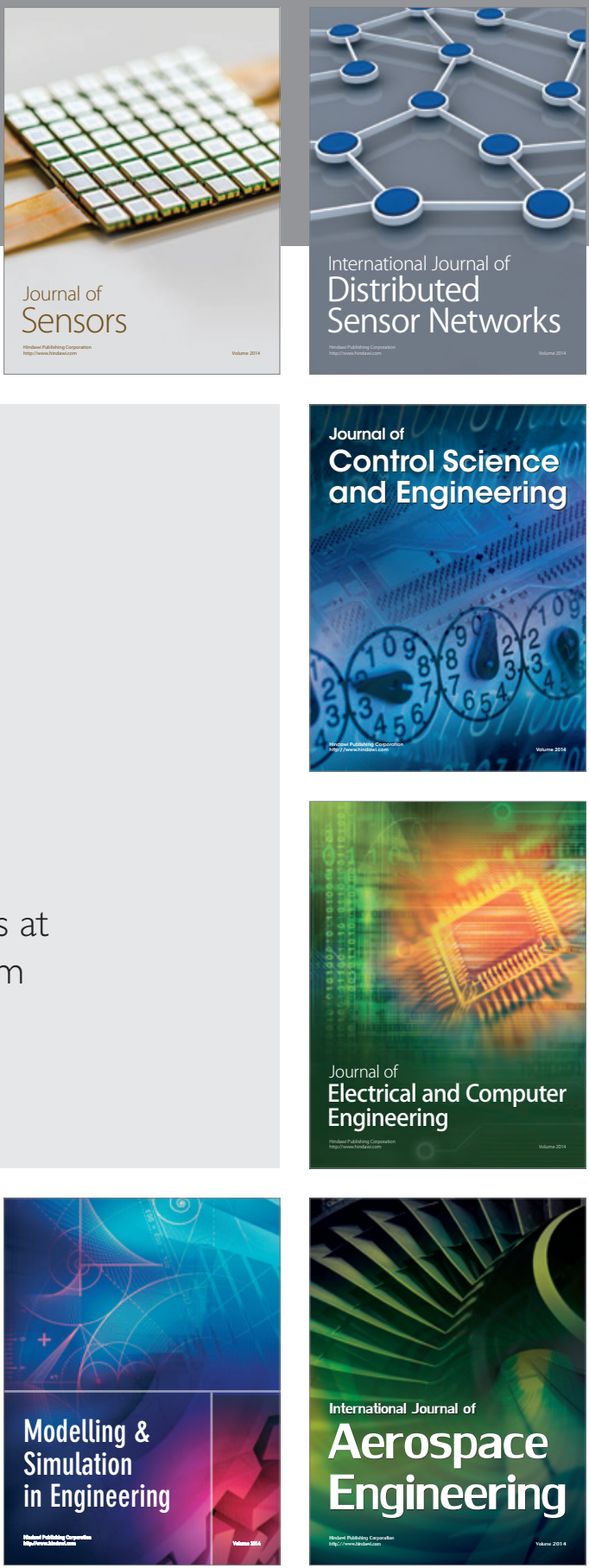

Journal of

Control Science

and Engineering
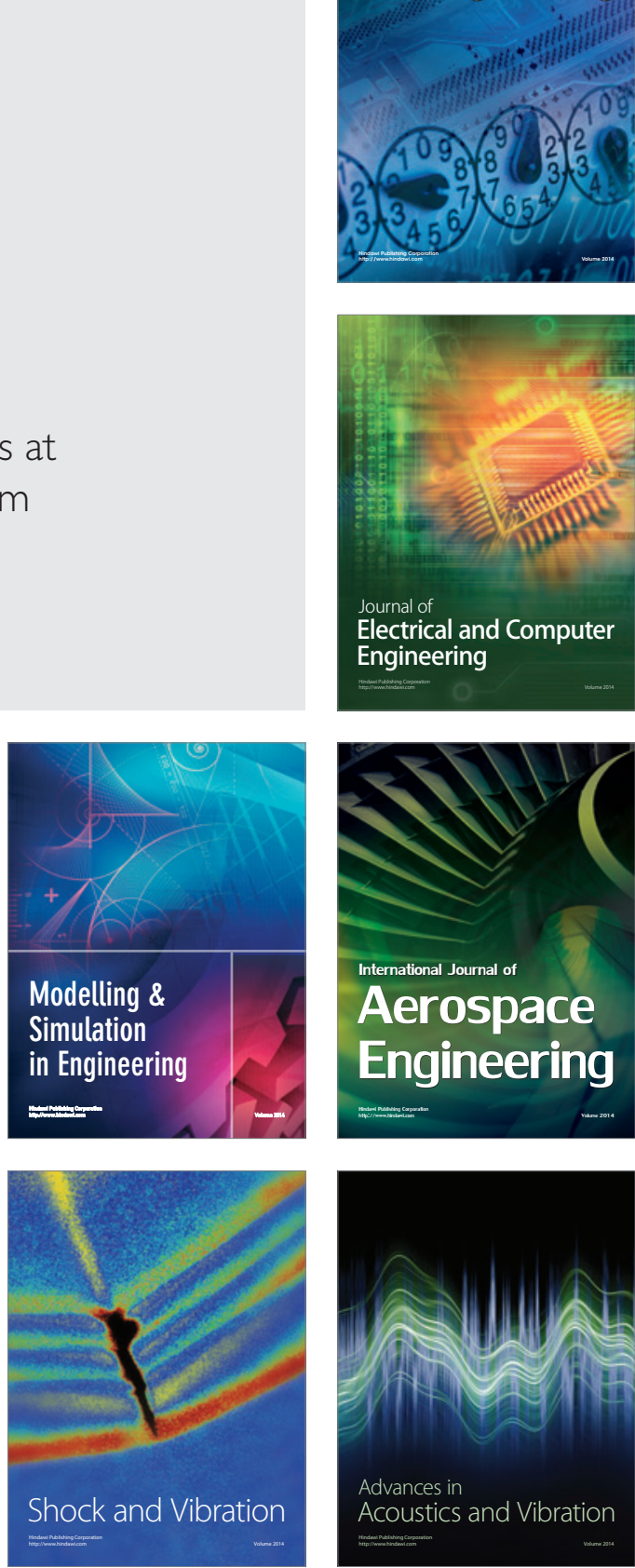